This item was submitted to Loughborough's Research Repository by the author.

Items in Figshare are protected by copyright, with all rights reserved, unless otherwise indicated.

\title{
Strategic dalliances as an enabler for discontinuous innovation in slow clockspeed industries: evidence from the oil and gas industry
}

PLEASE CITE THE PUBLISHED VERSION

https://doi.org/10.1111/j.1467-9310.2008.00505.x

\section{PUBLISHER}

Blackwell (@ the authors)

VERSION

AM (Accepted Manuscript)

\section{PUBLISHER STATEMENT}

This work is made available according to the conditions of the Creative Commons Attribution-NonCommercialNoDerivatives 4.0 International (CC BY-NC-ND 4.0) licence. Full details of this licence are available at: https://creativecommons.org/licenses/by-nc-nd/4.0/

\section{LICENCE}

CC BY-NC-ND 4.0

\section{REPOSITORY RECORD}

Noke, Hannah, Robert K. Perrons, and Mathew Hughes. 2019. "Strategic Dalliances as an Enabler for Discontinuous Innovation in Slow Clockspeed Industries: Evidence from the Oil and Gas Industry". figshare. https://hdl.handle.net/2134/26379. 


\title{
Strategic Dalliances as an Enabler for Discontinuous Innovation in Slow Clockspeed Industries: Evidence from the Oil \& Gas Industry
}

First Submission: R\&D Management Submitted: $16^{\text {th }}$ July 2007

\author{
Hannah Noke \\ Nottingham Business School \\ Jubilee Campus, Wollaton Road \\ Nottingham NG8 1BB \\ United Kingdom \\ Tel: +44 (0) 1158466563 \\ Fax: +44 (0) 1158466650 \\ E-mail: hannah.noke@nottingham.ac.uk
}

\author{
Robert K. Perrons \\ Shell International Exploration \& Production \\ P.O. Box 51510 \\ New Orleans, LA 70151-1510 \\ USA \\ Mathew Hughes* \\ Nottingham Business School \\ Jubilee Campus, Wollaton Road \\ Nottingham NG8 1BB \\ United Kingdom \\ Tel: +44 (0) 1158467747 \\ Fax: +44 (0) 1158466650 \\ E-mail: mat.hughes@nottingham.ac.uk
}

*Corresponding author

\section{Acknowledgements}

The authors thank the managers and employees of Royal Dutch Shell plc and Twister BV who took part in this investigation. Financial support for this research was provided by the Intel Corporation, the UK Engineering and Physical Sciences Research Council (EPSRC), and the Natural Sciences and Engineering Research Council (NSERC) of Canada. All errors remain the responsibility of the authors. 


\title{
Strategic Dalliances as an Enabler for Discontinuous \\ Innovation in Slow Clockspeed Industries: \\ Evidence from the Oil \& Gas Industry
}

\begin{abstract}
The concept of "strategic dalliances"-that is, non-committal supply relationships that a firm can dip in and out of while simultaneously fostering long-term links with other suppliers-has emerged as a promising strategy by which organizations can create discontinuous innovations. But does this approach work equally well for every sector and how can they be effectively used to help generate discontinuous innovation? Towards assessing the role that industry clockspeed plays in the success or failure of strategic dalliances, we provide case study evidence from Twister BV, an upstream oil and gas technology provider, and show that strategic dalliances can be an enabler for the discontinuous innovation process in slow clockspeed industries. Implications for research and practice are discussed and conclusions from our findings drawn.
\end{abstract}

Key words: Discontinuous innovation; oil and gas; clockspeed; strategic dalliances. 


\section{Introduction}

Discontinuous innovations (hereafter, DIs) can and frequently do weaken the competitive positioning of industry incumbents (Abernathy and Clark, 1985; Christensen, 1997). Nevertheless, literature extols their value as a strategic tool, and therefore actively encourages existing firms to use DIs to lead their respective industries (Bessant et al., 2005; Leifer et al., 2000). To this end, several strategies have been identified by which an established firm can broaden the radius of ideas and technological capabilities it has access to. Above all, developing links with external organizations has received repeated interest (Chesbrough, 2003; Rigby and Zook, 2002). The concept of 'strategic dalliances'-that is, non-committal supply relationships that a firm can dip in and out of while simultaneously fostering longterm links with other suppliers - has emerged from this body of research as an approach that is particularly well suited for discovering and developing ideas that lend themselves to the creation of DIs (Phillips et al., 2006).

Building on prior work in the area of DIs and strategic dalliances, questions are raised as to whether strategic dalliances are equally appropriate for every industry since little research exists to demonstrate how firms can benefit from such weaklyformed relationships. To this end, we introduce ideas and evidence from research in the area of industry clockspeed to examine these issues. Evidence suggests that firms' strategic actions in fast-paced industries differ from those in slow-paced industries, but, a paucity of studies into these differences exists (Nadkarni and Narayanan, 2007). Indeed, research suggests that firms in fast-paced industries benefit from internal strategic flexibility (Nadkarni and Narayanan, 2007) and close relationships with key suppliers (Koka and Prescott, 2002). Conversely, in slow-paced industries, these actions may not be adequate bases for competition on the grounds that availability of 
time affords firms greater opportunity to gradually identify opportunities through persistent exposure to novel information from a broad range of weak ties to make radical breakthroughs (Hansen, 1999; Nadkarni and Narayanan, 2007).

One approach that may be viable to slow-paced industries is the adoption of loosely-coupled relationships, where firms gain access to novel information from a breadth of non-committal relationships that can inform the creation of DI. This is in contrast to close relationships which are typified by redundancy in knowledge (Hansen, 1999). Strategic dalliances offer a novel counterview to the majority of studies implying the need for close alliances in efforts to foster DI. We explore such a proposition by presenting case study evidence focusing on the early days of Twister BV, a Netherlands-based upstream oil and gas technology provider. The work contributes to our understanding of strategic dalliances, DI, and industry clockspeed. We map avenues for futures research and the practical implications of this evidence to managers who are trying to create DIs.

\section{Literature Review and Propositions}

\section{The Motive for Fostering Discontinuous Innovation}

While it is widely recognized that innovation is essential for the future prosperity of organizations (Afuah, 1998; Bessant and Francis, 1999), the literature also acknowledges that not all innovations are the same. Some technologies are more or less incremental in nature, and modestly improve on a concept that is already available in the market. Others, by stark contrast, conspicuously disturb various states of equilibrium in an industry. Often characterized as "radical," "competencedestroying,” or “disruptive,” these DIs are capable of bringing about major upheavals in the industries they impact and fundamentally transforming relationships between customers and suppliers, restructuring marketplace economics, displacing current 
products, and creating entirely new product categories (Day and Schoemaker, 2004; Leifer et al., 2001; Rothaermel, 2002; Tushman and Anderson, 1986).

The introduction of a DI can weaken the competitive positioning of industry incumbents (Abernathy and Clark, 1985; Christensen, 1997). But incumbent firms have also been criticized for their inability to create DIs. Prior investigations in this area explain this by noting that what managers "have been able to do in the past strongly conditions what they can hope to do in the future” (Pavitt, 1990, p.18). Moreover, legacy organizational structures and know-how often encumber existing firms that are trying to create and foster DIs (Tushman and Anderson, 1986).

Despite the fact that DIs have brought about the demise of several high-profile industry leaders, other existing firms have prospered under these conditions (Leifer et al., 2000). In the face of a DI, "some incumbent organizations can and do adapt, survive, and regain historic performance levels” (Hill and Rothaermel, 2003, p.257). Some existing firms have also leveraged a DI to expand their business in a market segment that they created outside of their usual customer base (Gilbert, 2003). The "high stakes" nature of DIs and the potential for pronounced market growth have motivated researchers to help incumbent firms identify and successfully manage this sort of technological change (Afuah, 1998; Leifer et al., 2001). Other studies go further by recommending that existing firms should actively create DIs as a strategic tool for leading their respective industries (Bessant et al., 2005; Leifer et al., 2000).

To help organizations facing this challenge, the literature prescribes that established firms develop links with external organizations to broaden the radius of ideas and technological capabilities it has access to (Chesbrough, 2003; Quinn, 2000; Rigby and Zook, 2002). The concept of "strategic dalliances” has emerged from this 
body of research as an approach that is particularly well suited for discovering and developing ideas that lend themselves to the creation of DIs.

\section{Strategic Dalliances}

Establishing and maintaining long-term R\&D relationships with outside organizations has proved to be a highly successful model of innovation for some firms (Cavusgil et al., 2003; Quinn, 2000). But this tactic may not yield the kinds of revolutionary ideas that frequently underpin DIs. Industry-changing technologies often entail doing things differently, and tend to represent a dramatic departure from accepted norms and procedures (Phillips et al., 2006). The literature exploring the origins of DIs highlights the frequently serendipitous nature of the relationships behind these discoveries (Holton et al., 1996; Phillips et al., 2006). Many of the significant and commercially celebrated DIs that have emerged over the years have not been the result of tightly managed research agendas, but were instead brought about by a convoluted process of chance and unique circumstances (Afuah, 1998). An organization's “peripheral vision", the ability to detect an understand technological and market trends beyond its core discipline, has been identified as a key factor in its ability to take advantage of these serendipitous opportunities (Day and Schoemaker, 2004). To this end, Phillips et al. (2006) prescribe "strategic dalliances” as a strategy for maximizing an organization's chances of discovering a good idea outside of its own core discipline.

Strategic dalliances are rooted in a firm's ability to “develop a broad range of non-committal supply relationships that it can 'dip in and out of,' or dally with, in concurrence with its longer-term strategic partnerships” (Phillips et al., 2006, p.455). Unlike more traditional alliances involving the development and maintenance of longterm links, strategic dalliances "are not open-ended nor guided by established norms 
or routines. Cultural compatibility is not a requisite... The low level of commitment allows the relationship to be broken off when there is clearly no chance of success" (Phillips et al., 2006, p.455). These looser affiliations also make possible the exploration of "a new sector or new knowledge with little or no resource commitment” (Phillips et al., 2006, p.455).

It is important to emphasize that the strategic dalliances approach to creating DIs is not intended to supplant more traditional types of R\&D collaboration; rather, it ought to augment these efforts. Prior research has shown that organizations are able to manage incremental innovation focused on their core businesses while simultaneously trying to develop DIs through practices of experimentation and discovery which require different and broader kinds of knowledge to be combined together (Christensen, 1997; Tushman and O'Reilly, 1996). Dhanaraj and Parkhe (2006), supported by Hansen (1999) and Granovetter (1973), theorize how a firm's innovation network often acts as loosely coupled systems of autonomous firms highlighting that a persistent set of weak ties (distant but nonredundant bridges of relationships that a firm holds with a variety of stakeholders) are valuable because of their efficient knowledge-sharing properties and ability to provide access to novel information by bridging disconnected groups and individuals. Such strategic dalliances allow exposure to novel information that could aid in the creation of DI.

While the concept of strategic dalliances holds significant promise as a means for fostering DIs and acting as a catalyst for radically new technologies, there is not yet enough evidence to establish that this approach is equally prudent for every sector (c.f., Phillips et al., 2006). Different industries often behave very differently, and each is coloured by the subtleties of its history and operating environment (Porter, 
1980). One important factor that might impact the success or failure of strategic dalliances is the clockspeed of the industry in which it operates.

\section{The Role of Clockspeed}

Some industries evolve faster or slower than others-that is, they operate at different clockspeeds (Fine, 1998). An industry’s clockspeed is effectively “the velocity of change in the external business environment” (Mendelson and Pillai, 1999, p.1) that sets the pace of a firm's internal operations. Fine (1998) offers several realworld examples that capture the essence of fast (e.g., semiconductors and athletic footwear), medium (e.g., automobiles and pharmaceuticals), and slow clockspeed industries (e.g., petrochemicals and commercial aircraft). Whilst it is true that every organization exhibits both fast and slow clockspeed characteristics from time to time-for example, slowly changing industries may be faced with periods of frenetic activity, and fast-paced sectors might become stable for a while-most measures of clockspeed are aimed at long-term industry trends and norms.

The literature demonstrates that an industry's clockspeed does impact various aspects of how firms manage their relationships with outside organizations (Akkermans et al., 2003; Harrigan, 1984; Nadkarni and Narayanan, 2007). Accordingly, the use of strategic dalliances as a means for establishing loose ties with outside organizations and then quickly undoing them may be more successful in some industries than others. Faster moving industries like the semiconductor sector, for example, might change and evolve very quickly whether they are actively pursuing dalliance-style relationships or not. The existing forces of evolutionary change driving this kind of industry may naturally open up a broad range of opportunities for learning about new ideas in other organizations. But at the other end of the spectrum, some sectors that evolve extremely slowly-like the upstream oil and gas industry- 
might not normally be exposed to as many new organizations and ideas simply because of the more restrained pace of their industry's clockspeed. In essence, the overriding competitive priority for DI is conditioned by slow industry clockspeed. But strategic dalliances increase exposure to novel information that can spark disparate ideas to be connected, thus restoring interest and need for DI. Accordingly, these organizations may therefore benefit most from strategic dalliances.

Proposition 1: Strategic dalliances are an effective enabler for the discontinuous innovation process in slow clockspeed industries.

\section{Methodology}

A qualitative methodology was used because we sought to undertake a more complete, holistic, and contextual assessment of strategic dalliances and their role in fostering DIs (Jick, 1979). Following Yin (1994), we used a case study method because this is a preferred strategy when 'how' or 'why' questions are being posed and when the focus is on a contemporary phenomenon. Using qualitative case studies helps to establish the internal validity of the data also because " $[\mathrm{w}]$ hen a relationship is supported, the qualitative data often provide a good understanding of the dynamics underlying the relationship” (Eisenhardt, 1989, p.542) and can make clear when an apparent relationship is spurious or the result of an additional variable not originally considered in the research design.

The data for this case study was collected via an initial roundtable discussion and a process of semi-structured interviews involving senior-level managers at Shell International's Exploration \& Production division and Twister BV between April 2002 and August 2003. Each of the discussions was loosely guided by a list of questions, but departures from each conversation's agenda were permitted in the interest of exploring new and potentially fruitful points. The format of the discussions 
was accordingly adapted and changed slightly from one discussion to the next to pursue interesting and particularly relevant new facets of the case study as they emerged.

Yin (1994) and Flick (1998) both recommend using multiple sources of evidence in case studies to "triangulate" among various points of view and minimize the amount of subjectivity within the study. To this end, perspectives about key decisions were solicited from four senior managers within Shell and an equal number in Twister BV. This approach was used to arrive at conclusions that are broadly in agreement and reproducible. Observations and conclusions were then documented and shared with the participating managers to make sure that the case study accurately and fairly reflected their opinions and the events that led to the development of the Twister cyclone separator, a discontinuous innovation.

\section{Establishing Twister as a Slow Clockspeed Organization}

Despite Twister BV being only a few years old when this case study was compiled, Fine (1998) specifically identifies the petrochemicals sector as a slow clockspeed industry: new product technologies are typically introduced every 10-20 years, process technologies change every 20-40 years, and the sector tends to undergo a period of major organizational restructuring every 20-40 years. The upstream oil and gas industry supplies the principal inputs - that is, oil and natural gas - to the petrochemical sector, and many energy giants such as ExxonMobil, Shell, and BP have vertically integrated both the upstream and petrochemical elements of the oil and gas value chain. The two sectors are therefore tightly linked and have comparable rates of evolution. Thus, because Twister's products are exclusively intended for use by upstream oil and gas firms, it follows that Twister BV is also a slow clockspeed organization in a slow clockspeed industry. 


\section{Case Study}

\section{Company Description and Industrial Context}

Twister BV was officially a standalone company consisting of only 20 employees at the time of this case study, but it has always been attached in many ways to Royal Dutch Shell, one of Europe's largest integrated energy companies (Hoyos, 2004). Several of Twister's executive-level managers are former Shell employees who resigned from their positions within Shell to lead the new venture, and Twister BV's head office in the Netherlands is located only a few kilometres from Shell's Exploration and Production R\&D laboratories in Rijswijk.

Twister BV ultimately began when a handful of Shell executives diagnosed a longstanding problem within the energy industry in general, and specifically within their own company. They believed that the oil and gas sector could benefit significantly from the deployment of innovations, but observed that new technologies were absorbed into the industry very slowly. Considered by some to be "the world's biggest business” (Yergin, 1991, p. 779), the oil and gas industry has an uncommonly high profile in the global economy, and energy companies are therefore very sensitive about issues such as safety and reputation. In the words of one industry insider, "the cost of failure is very high” (Hilliard, 2003, p. 29). An unfortunate consequence of this heightened sensitivity, however, is that oil and gas firms have historically been very conservative, and are often reluctant to make use of promising new technologies. $^{1}$

\footnotetext{
${ }^{1}$ This is not to say that the industry has never made any bold forays into new technology areas. In a bid to diversify outside of the energy industry, Exxon invested nearly $\$ 2$ billion in the 1970s to develop office equipment such as word processors, fax machines, and electronic typewriters. But as Utterback (1994) explains, the company later "retreated to the oil patch after selling its product line to Lanier for pennies on the dollar" (p. 14).
} 
One particular outside technology that caught Shell's attention was a novel system for removing condensed droplets from flowing gas streams in air conditioning systems. Noordwijk Technologies ${ }^{2}$, a Dutch design and engineering company with nearly 20,000 employees, did not originally have the oil and gas market in mind when it developed this technology. Nonetheless, a manager in Shell heard about Noordwijk's research in this area, and wondered if their innovation could separate droplets from natural gas as well as it could in air conditioners.

Twister BV was an extremely small enterprise in its early days, and relied heavily on its outside suppliers as a result. When the company was first trying to introduce the concept of cyclone separators to the oil and gas industry, Noordwijk Technologies was responsible for most aspects of the design and production. Specific machining requirements were met by Noordwijk’s existing supplier base, and the finished products were assembled by Noordwijk technicians. Twister BV’s engineers and management team at the time, many of whom had only recently left Shell, had very little previous exposure to the new technology. In its nascent stages, the firm effectively assumed the role of a "systems integrator" (Ernst and Steinhubl, 1997), offering management experience, millions of dollars in capital investment, and infield opportunities for trying out prototypes.

In spite of Noordwijk’s prominent role in the design and production process, the new technology also required a significant amount of outside input with regards to the aerodynamic and thermodynamic behaviour of fluids travelling at supersonic speeds. These phenomena are relatively well understood within the aircraft and aerospace sectors, but engineers in these industries tend to focus principally on supersonic flow over wings and along fuselages. It was not known if or how the

\footnotetext{
${ }^{2}$ This is not the real name of the company.
} 
principles of supersonic flow might be subtly different when rotating within a tube. Towards filling these holes in existing research, the Twister team enlisted the help of a handful of researchers from universities in the UK and the Netherlands to develop highly specialized modelling software for the CFD, thermodynamic, and manufacturing aspects of the Twister separator technology.

Today, the company regards this know-how as an important part of its competitive advantage, and retains a large fraction of its R\&D work in-house so that it will be able to do almost all of its own design concept and process engineering work in the future. In fact, Twister BV's engineers have become so adept in this area that the company now sells its expertise in CFD and natural gas processing systems on a consulting basis to other firms as a source of supplementary revenue. But the Twister team still maintains its collaborative research relationships with the outside laboratories it worked with in the early days, and recently launched a new R\&D link to Shell's high-tech Thornton Research Centre in the UK.

Not all of the relationships between Twister BV and its original partners are still intact, however. The firm's relationship with Noordwijk Technologies weakened considerably because Noordwijk’s senior managers did not share Twister's optimism about the future prospects of cyclone separator technologies in the oil and gas industry. Although Noordwijk continues to design and manufacture cyclone separators for air conditioning applications, the relationship between Noordwijk and Twister BV was severed only a few years after the development of the first Twister prototypes, leaving Twister BV as the only firm to apply the technology within the energy sector.

In addition to the R\&D and conceptual aspects of the technology, Twister's engineers have also taken over the basic mechanical design aspects of the 
manufacturing process. As before, however, the detailed design and production functions are still handed off to outside suppliers - but not the same ones that performed these tasks when Noordwijk Technologies was involved. Instead, Twister BV has developed new ties with a small number of very small, highly specialized supplier firms that each consists of between three and ten people. It is not a company policy to buy exclusively from smaller firms, but Twister's managers have observed that small suppliers tend to be flexible and more responsive to Twister's needs than their larger competitors. In the words of Twister's CEO and Technical Director, "The smaller contractors learn from us.” Key suppliers have sent their engineers to work alongside the Twister BV design team on a full-time basis for as long as two months. The CEO explains this practice by noting that, "Having a close relationship with these companies benefits us because they come to know the context we are working in, and they know our constraints.”

The company's preference for smaller suppliers does come at a price, however: Twister BV has to bear almost all of the costs associated with developing or acquiring new technologies. Almost none of the company's suppliers have financial resources that would allow them to invest in long-term R\&D. Also, because of the uniqueness and highly customized nature of the parts used in Twister separators, the results of any research investment by the suppliers would very likely be applicable only to Twister BV's products. Twister's managers do not engage in long-term contracts with supplying companies, and these firms are therefore reluctant to invest heavily in new technologies for which Twister BV would be the only customer.

But the absence of long-term contracts does not mean that Twister BV does not value its suppliers. Compared to their peers in the industry, Twister managers 
believe that they place a relatively high premium on long-term supplier relationships. Because the industry evolves quite slowly in comparison to other sectors, most of the technologies used on a day-to-day basis within the energy industry have been available for many years, and are widely available from a broad range of suppliers. The components used to construct most oil and gas processing facilities are largely modular in nature - that is, they have standardized interfaces, and similar components can be purchased from several vendors. This is not true for Twister's separators. Many of the parts within a Twister unit are made to precise specifications and require a considerable amount of know-how on the part of the suppliers. Twister BV accordingly values the relationships it has built within its supply base because of the high degree of expertise and specialized skills that collaborating firms must have to fulfil their roles competently.

The highly specific requirements for some aspects of the technology sometimes result in situations where Twister's managers have very few procurement options, and the company's supply base consequently extends to the US and many countries in Europe. For example, one of the internal components of the Twister separator is made from molybdenum steel, an alloy that is particularly resistant to corrosion. The variety of this steel that Twister BV requires is very rare, and can only be purchased from a single vendor in the US. Thus, while the company does engage in short-term relationships and eschews long-term contracts with the firms in its supply network, Twister BV concurrently maintains string inks with several of its suppliers.

\section{Discussion and Conclusions}

The intention of the study was to develop a richer understanding of the role played by strategic dalliances in slow-paced industries to ascertain if this strategy can 
enable DI. This paper has presented research that illustrates a detailed and in-depth case study of how a single firm operating within a slow-paced industry attempted to introduce DI into its industry by utilizing strategic dalliances.

Whilst not by design, the supply chain design used to create the first generations of the Twister cyclonic separator closely resembled those espoused in the strategic dalliances literature. Initially, the firm branched out and established a more relaxed partnership with Noordwijk Technologies, a company that had no prior exposure to the oil and gas sector. In the spirit of strategic dalliances, the affiliation between Twister BV and Noordwijk Technologies was loose enough that it could be dissolved when the two firms began to disagree on the future of this technology. The same pattern was followed with its later relationships with universities and small firm suppliers for example. But it was necessary for Twister BV to develop and foster long-term relationships with several of its suppliers because of its need for specialty materials and know-how.

In light of Noordwijk Technology's significant contribution to the conceptlevel design that eventually led to the Twister separator, it is quite unlikely that either Twister BV—or, indeed, the rest of the oil and gas industry—would have been able to create this technology without Noordwijk's help. Indeed, the very notion of the Twister cyclonic separator came from their research and subsequent exposure to novel information through loosely coupled links with Noordwijk. Most of the leading firms in the upstream oil and gas sector are incumbents that have been in business for decades, and the nature of relationships among companies in the industry is such that almost any kind of innovation—especially discontinuous ones—is very difficult (Daneshy and Donnelly, 2004). Senior managers in the sector readily concede that there are structural barriers between oil companies and their longstanding suppliers 
that provide disincentives to innovate (Donnelly, 2006). But by creating nonredundant loose relationships through strategic dalliances, Twister BV was able to overcome these structural barriers by idiosyncratically drawing on relationships as and when necessary to develop and commercialize the DI. It would not have been possible to achieve the DI due to lack of knowledge and structural barriers had they not been able to draw on the novel knowledge of others at key points. It therefore follows that the proposition receives support: strategic dalliances were an effective enabler for the DI process in this industry based on the case evidence.

\section{Implications for Theory}

While strategic dalliances may be a fruitful strategy to every organization from time to time, we believe that some industries may be naturally and structurally predisposed to benefiting from this approach more than others. The oil and gas industry has traditionally been a conservative sector populated by a fairly predictable group of operators and vendors. Consequently, genuinely discontinuous ideas like those used to make the Twister separator do not surface very often-and when they do, they frequently face resistance. Strategic dalliances therefore offered the oil and gas industry an opportunity to inject fresh ideas into a historically conservative market and allow firms to better develop and commercialize those opportunities through innovation. Through dalliances, the firm encounters novel information and a disparate range of knowledge that facilitates the generation of unique insight that can foster DI.

Our conclusion fits with findings of other studies to strongly suggest that slow clockspeed industries are more likely to benefit from strategic dalliances than their fast clockspeed counterparts. Specifically, Nadkarni and Narayanan (2007) discover that firms in fast clockspeed industries gain competitive advantage from carefully 
managed internal firm design that embeds strategic flexibility. The velocity of change creates business challenges at the micro firm level in the sense that if their internal systems and processes prevent the active throughput of information, creativity and innovation, and flexibility to change, their business practices and product innovations will not keep pace with the rate of industry change. The difficulty, however, is that industry clockspeed is not necessarily a marker of the rate at which DI takes place. Fine (1998) gives an example of the semiconductor industry in which innovation is typically incremental but in the circuit board industry, change is often discontinuous. Nonetheless, our observation that strategic dalliances appear favourable as a means to foster DI in slow clockspeed industries supports Nadkarni and Narayanan’s (2007) view that strategic actions of firms in slow-paced industries differs to those in fastpaced industries. In this way, this evidence contributes to the classification schemes underpinning strategic dalliances. Still, further research is needed to further understand the differences in strategic action.

\section{Implications for Industry}

The data's support of our proposition may also impact the strategic thinking of managers in the marketplace. Firms in slow clockspeed industries can learn from Shell and Twister BV's experience with strategic dalliances, and may therefore be able to use it as a way to increase their own organization's DI capacity. As noted earlier, some incumbent firms have used DIs very effectively to expand their business in new market segments outside of their usual customer base (Gilbert, 2003), and strategic dalliances may be a useful mechanism by which to achieve this objective. The difficulty, however, is in maintaining a range of weak ties in the form of strategic dalliances in which the social capital generated by the firm allows it to access valuecreating knowledge and resources despite the fact that relationships are not deeply 
entrenched. This presents somewhat of a contradiction in the sense that literature on social capital, and to a lesser extent embeddedness, indicates that firms should develop in-depth relationships to enhance embeddedness which increases exposure to novel information (Ireland et al., 2001).

Conversely, this evidence along with our prior discussion, might give managers in fast clockspeed sectors reason to pause and reflect prior to actively deploying a strategic dalliances strategy. The oil and gas industry clearly benefited from this approach because it desperately needed exposure to fresh ideas and outside perspectives. By contrast, however, a faster clockspeed industry may already have access to so many new ideas that it has difficulty digesting the ones it already has. Resource-based theory contends that the energy and attention of the company's managers are "clearly limited in [their] possible scope simply because the capacity of any human being is finite” (Penrose, 1980, p.18). Thus, strategic dalliances might not help in environments where a manager already has plenty of new DI possibilities to choose from. Expending any amount of resources or managers' attention in the pursuit of additional inspiration may therefore be of questionable value in these situations.

\section{Directions for Future Research}

While this investigation demonstrated how and why strategic dalliances work for slow clockspeed industries, it offers no direct evidence to suggest that this strategy does not also work for fast clockspeed sectors. Findings by Nadkarni and Narayanan (2007) indicate that internal firm design factors govern competitive ability in fastclockspeed industries rather than any kind of dalliance-style external relationships. Unlike this investigation, however, they did not specifically examine DI. Thus, one particularly promising area for future research would be to look specifically at 
supplier relationships within fast clockspeed industries to confirm that, as suggested in this paper, fast-moving companies benefit only marginally from strategic dalliances. A broader quantitative analysis involving many firms of varying clockspeeds would also help to categorize the strategic dalliances landscape en route to knowing when this strategy should be prescribed.

The second issue for future research is to examine the workings of dalliances. The effective management of strategic alliances and more broadly networks has received growing attention over the years (e.g., Ireland et al, 2001). However, our understanding of how to effectively manage and govern strategic dalliances, a different type of relationship altogether, is very limited. Given its value and the fact that it does not cleanly subscribe to prominent theories such as social capital, there is a need for greater research into how these relationships can be made to work in the firm's favour. We have shown in this investigation that they can be powerful aids to unlocking resources and novel information that can, in turn, aid the DI process. But key questions remain. How, for example, does such a process begin, and how can it be effectively managed without these ties being severed? 


\section{References}

Abernathy, W. J. and Clark, K. B. (1985) Innovation: mapping the winds of creative destruction. Research Policy, 14, 1, 3-22.

Afuah, A. (1998) Innovation Management: Strategies, Implementation, and Profits. New York: Oxford University Press.

Akkermans, H., Meijboom, B., and Voordijk, H. (2003) Supply chain co-ordination and industry clockspeed: an exploratory study. In Spina, G., Vinelli, A., Cagliano, R., Kalchschmidt, M., Romano, P. \& Salvador, F. (Eds.) Proceedings from EurOMA-POMS Conference, June 16-18. Lake Como, Italy: SGEditoriali.

Bessant, J. and Francis, D. (1999) Using learning networks to help improve manufacturing competitiveness. Technovation, 19, 6/7, 373-381.

Bessant, J., Lamming, R., Noke, H., and Phillips, W. (2005) Managing innovation beyond the steady state. Technovation, 25, 12, 1366-1376.

Cavusgil, S. T., Calantone, R. J., and Zhao, Y. (2003) Tacit knowledge transfer and firm innovation capability. Journal of Business and Industrial Marketing, 18, $1,6-21$.

Chesbrough, H. W. (2003) The era of open innovation. MIT Sloan Management Review, 44, Spring, 35-41.

Christensen, C. M. (1997) The Innovator's Dilemma. Boston, MA: Harvard Business School Press.

Daneshy, A. and Donnelly, J. (2004) A JPT roundtable: the funding and uptake of new upstream technology. Journal of Petroleum Technology, 56, 6, 28-30.

Day, G. and Schoemaker, P. (2004) Peripheral vision: sensing and acting on weak signals. Long Range Planning, 37, 2, 117-121.

Dhanaraj, C. and A. Parkhe (2006) Orchestrating innovation networks. Academy of Management Review, 31, 3, 659-669.

Donnelly, J. (2006) Q\&A: Rick Fontova, Senior Vice President, Enventure Global Technology. Journal of Petroleum Technology, 58, 11, 20-23.

Eisenhardt, K. M. (1989) Building theories from case study research. Academy of Management Review, 14, 4, 532-550.

Ernst, D. and Steinhubl, A. M. J. (1997) Alliances in upstream oil and gas. The McKinsey Quarterly, 2, 144-155.

Fine, C. H. (1998) Clockspeed: Winning Industry Control in the Age of Temporary Advantage. Reading, MA: Perseus Books.

Flick, U. (1998) An Introduction to Qualitative Research. London: Sage Publications.

Gilbert, C. (2003) The disruption opportunity. MIT Sloan Management Review, 44, Summer, 27-32.

Granovetter, M. S. (1973) The strength of weak ties. American Journal of Sociology, 6, 1360-1380. 
Hansen, M. T. (1999) The search-transfer problem: the role of weak ties in sharing knowledge across organization subunits. Administrative Science Quarterly, 44, $1,82-111$.

Harrigan, K. R. (1984) Formulating vertical integration strategies. Academy of Management Review, 9, 4, 638-652.

Hill, C. W. L. and Rothaermel, F. T. (2003) The performance of incumbent firms in the face of radical technological innovation. Academy of Management Review, 28, 2, 257-274.

Hilliard, R. (2003) Profile: Erik Vollebregt. Changes: Shell International Exploration and Production BV's External Magazine.

Holton, G., Chang, H., and Jurkowitz, E. (1996) How a scientific discovery is made: a case history. American Scientist, 84, 4, 364-376.

Hoyos, C. (2004) Investors push for changes at Shell. Financial Times (UK edition), February 5, 19.

Ireland, R. D., Hitt, M. A., and Vaidyanath, D. (2001) Alliance management as a source of competitive advantage. Journal of Management, 28, 3, 413-446.

Jick, T. D. (1979) Mixing qualitative and quantitative methods: triangulation in action. Administrative Science Quarterly, 24, 4, 602-611.

Koka, B. R. and Prescott, J. E. (2002) Strategic alliances as social capital: a multidimensional view. Strategic Management Journal, 23, 795-816.

Leifer, R., McDermott, C. M., O'Connor, G. C., Peters, L. S., Rice, M., and Veryzer, R. W. (2000) Radical Innovation: How Mature Companies Can Outsmart Upstarts. Boston, MA: Harvard Business School Press.

Leifer, R., O'Connor, G. C., and Rice, M. (2001) Implementing radical innovation in mature firms: the role of hubs. Academy of Management Executive, 15, 3, 102113.

Mendelson, H. and Pillai, R. R. (1999) Industry clockspeed: measurement and operational implications. Manufacturing \& Service Operations Management, 1, 1, 1-20.

Nadkarni, S. and Narayanan, V. K. (2007) Strategic schemas, strategic flexibility, and firm performance: the moderating role of industry clockspeed. Strategic Management Journal, 28, pp.243-270.

Pavitt, K. (1990) What we know about the strategic management of technology. California Management Review, 32, 3, 17-26.

Penrose, E. T. (1980) The Theory of the Growth of the Firm. Oxford: Basil Blackwell.

Phillips, W., Lamming, R., Bessant, J., and Noke, H. (2006) Discontinuous innovation and supply relationships: strategic dalliances. R\&D Management, 36, 4, 451-461.

Porter, M. E. (1980) Competitive Strategy: Techniques for Analyzing Industries and Competitiors. New York: The Free Press.

Quinn, J. B. (2000) Outsourcing innovation: the new engine of growth. Sloan Management Review, 41, Summer, 13-28. 
Rigby, D. and Zook, C. (2002) Open-market innovation. Harvard Business Review, 80, October, 5-12.

Rothaermel, F. T. (2002) Technological discontinuities and interfirm cooperation: what determines a startup's attractiveness as alliance partner? I. E. E. E. Transactions on Engineering Management, 49, 4, 388-397.

Tushman, M. L. and Anderson, P. (1986) Technological discontinuities and organizational environments. Administrative Science Quarterly, 31, 3, 439465.

Tushman, M. L. and O'Reilly, C. A. (1996) Building ambidextrous organizations: managing evolutionary and revolutionary change. California Management Review, 38, 4, 8-30.

Utterback, J. M. (1994) Mastering the Dynamics of Innovation. Boston, MA: Harvard Business School Press.

Yergin, D. (1991) The Prize: The Epic Quest for Oil, Money, and Power. New York: Touchstone.

Yin, R. K. (1994) Case Study Research: Design and Methods. Thousand Oaks, CA: Sage Publications. 